\title{
Assessment of the phytochemical components of Mangifera indica (leaf) and Musa paradisiaca (roots) extracts and their antibacterial activity against some common pathogenic bacteria.
}

\author{
Nwankwo, I.U. and Osaro-Mathew, R.C. \\ Department of Microbiology, college of Natural Sciences, Michael Okpara University of Agriculture, Umudike, \\ P.M.B. 7267 Umuahia, Abia State.
}

\begin{abstract}
The present study was carried out to find out the antibacterial activity and phytochemical study of Mangifera indica (leaf) and Musa paradisiaca (root) extracts against some common pathogens. In this study, the leaf and root extracts of $M$. indica and $M$. paradisiaca respectively were subjected to screening against Staphylococcus aureus, Escherichia coli, Streptococcus pneumoniae, Proteus mirabilis and Pseudomonas aeruginosa. Antimicrobial analysis was done by using agar well diffusion and the MIC values were determined by using macro-broth dilution method. The ethanol extract of M.paradisiaca produced the highest antibacterial activity against S.aureus $(10.40 \pm 0.04)$ followed by the ethanol extract of M.indica against P.mirabilis $(9.52 \pm$ 0.06). The antimicrobial activity of standard antibiotics Gentamycin and Trimethoprim were studied in comparison with the plant extracts. The phytochemical analysis showed the presence of alkaloid, flavonoid, tannins, saponins, glycosides and anthraquiones. Biological active compounds present in these plant extracts have always been of great interest to scientist as they play an important physiological and etiological role hence they are of great commercial interest with multiple application on pharmaceutical industries.
\end{abstract}

Keywords: Antibacterial activity, Extracts, Phytochemical study, some common pathogens.

\section{Introduction}

The issue of natural medicine is fast gaining ground all over the world (Amaechi, 2003). Despite controversies, pharmacists are coming to terms with natural medicine being an important aspect of health care delivery. The plant kingdom still held many species of plants containing substances of medicinal value which were yet to be discovered (Nwankwo and Amaechi, 2013). Even though large numbers of plants were constantly being screened for their possible pharmacological value, it was estimated that only about $1 \%$ of Nigerian medicinal plants had been subjected to scientific evaluation for potential chemotherapeutic value (Nwankwo et $a l, 2012)$.

The beneficial medicinal effects of plant materials typically results from the combination of secondary products present in the plant. Today, nearly $50 \%$ of the thousands of drug commonly used and prescribed are either derived from plants sources or contain chemical imitations of plants compounds (Ayodele, 2003). The medicinal actions of plants are unique to particular plant species or groups are consistent with this concept as the combination of secondary products in a particular plant is taxonomically distinct.

The search for components with antimicrobial activity has gained increasing importance in recent times due to growing worldwide concern about the alarming increase in the rate of infection by antibiotic resistant microorganisms (Davies, 1994).

People are now choosing to visit therapists because they are disillusioned and dissatisfied with conventional medicine. With the increasing charges of modern medicine and the growing rate of adulterated drugs, sick people are beginning to consider the use of herbs for medicine (Ewujowoh, 1993).

Many plant species have been utilized as traditional medicines but it is necessary to establish the scientific basis for the therapeutic actions of traditional plant medicines as these may serve as the source for the development of more effective drugs.

Plant Musa paradisiaca whose common name is plantain is a household plant. The leaves are evergreen. The trunk is soft and contains a lot of fluid. The green leaf of plantain is very useful for treating diabetes (Isibor and Kingsley, 1993). The whitish fluid that shows when plantain leaf is cut is very effective for the treatment of wounds, especially fresh wounds. The juice stops the flow of blood very quickly (Adodo, 2002). The most medicinal part of plantain called the sap is present in every part of the plant (Isibor and Kingsley, 1993). The plantain plant is rich in inulin, alkaloids, tannins and noradrenalin (Adodo, 2002). They are reported to be active against dysentery, ulcer, skin infections, prostitis, diabetes and gonorrheal/syphilis (Grand et al, 1990). 
Mangifera indica commonly known as mango belong to the family Anarcadiacae. It is widely used as a source of food, medicines and timber. In Nigeria, different parts of Mangifera indica (mango tree) are commonly used as herbal preparations in the treatment of tooth ache, gastrointestinal disorders, dysentery, diarrhea, gastrointestinal tract infections, respiratory and urinary tract infections (Adodo, 2002). It has been noted that infection of leaves and stems extract of Mangifera produce in dogs and rabbits hypotensive action (Gill, 1992). All organs of the plant are rich in tannins in the leaves of the West African species anthrocyanidins, Leucoanthrocyanins, catechic and gallic tannins, mangiferin, kaempeferol and quercitin were reported (Bever, 1986).

\section{Materials And Method}

2.1 Plant materials: Mangifera indica (leaf) and Musa paradisiacal (root) were collected from Umulogho village in Obowo L.G.A. of Imo State and the taxonomic identification was carried out at the Forestry Department of Michael Okpara University of Agriculture, Umudike, Umuahia, Abia State.

\subsection{Plant extraction}

2.2.1 Ethanol extraction: Leaves of Mangifera indica and roots of Musa paradisiaca (50g each) were washed with distilled water to remove excess soil. The freshly collected plant samples were finely grounded and soaked in 95\% ethanol overnight. The crude extracts were filtered with Whatman No. 1 filter paper and thereafter, concentrated by means of a rotary evaporator (Buchi Rotavapor R-200) at a temperature of $40^{\circ} \mathrm{C}$ to allow optimal separation of ethanol and active compounds. This process was repeated four times to ensure maximum yield of extracted compounds. The extracts were further concentrated to dryness by means of a freeze-dryer to extract any excess water from the samples. The obtained samples of Mangifera indica leaves and Musa paradisiaca roots were stored in $4^{\circ} \mathrm{C}$ cooler room and redissolved in ethanol to desired concentration $(100 \mu \mathrm{l} / \mathrm{ml})$ for the further use.

2.2.2 Aqueous extraction: The plant materials were washed of excess soil with distilled water. The leaves and roots materials were finely grounded respectively followed by an infusion in hot $\left(95^{\circ} \mathrm{C}\right)$ distilled water. The samples were left overnight. The crude extracts were filtered with Whatman No. 1 filter paper and subsequently frozen at $-70^{\circ} \mathrm{C}$. The frozen extracts of the plants were freeze-dried to a powder, which was redissolved in distilled water to desired concentration $(100 \mu \mathrm{l} / \mathrm{ml})$ for experiments. The remaining unused plant materials were dried at $40^{\circ} \mathrm{C}$ and stored in brown paper bags at room temperature for further use.

2.3 Microorganisms: The test organisms include Staphylococcus aureus, Escherichia coli, Streptococcus pneumoniae, Proteus mirabilis and Pseudomonas aeruginosa. They were obtained from Federal Medical Center Owerri Microbiology Laboratory.

2.4 Preliminary phytochemical analysis: Qualitative phytochemical analysis of mangifera indica leaf and Musa paradisiaca root powder were carried out following standard procedures stipulated by Adegoke and Adebayo (2009 a and b) and Trease and Evans (1984). The tests were carried out as follows: Alkaloid (1.0g plant material in $10 \mathrm{ml}$ of aqueous HCL on a steam bath filtered) A $1 \mathrm{ml}$ filtrate + few drops of Dragendorff's reagents, brownish red precipitate indicated the presence of alkaloid.

Tannins: $1.0 \mathrm{~g}$ of the extract in $10 \mathrm{ml}$ distilled water $+10 \mathrm{ml}$ bromine water. Decolourization of bromine water indicated the presence of tannins. Saponins (Frothing test) $0.5 \mathrm{ml}$ filtrate $+5 \mathrm{ml}$ distilled water. Frothing persistence during warming meant saponin present. Flavonoids; $2 \mathrm{~g}$ of extract in $10 \mathrm{ml}$ distilled water $+10 \mathrm{ml}$ ethylacetate then heated for 3 minutes in water bath, cold and filtered. A $4 \mathrm{ml}$ filtrate $+1 \mathrm{ml}$ dilute ammonia solution.

Yellow colouration of the ammonical layer (lower alkaline layer after shaking) indicated the presence of flavonoids.

Anthraquinones: $1.0 \mathrm{~g}$ of the extract shaken with benzene, a layer gets separated and half of its own volume, $10 \%$ ammonia solution was added pink-red colouration indicated the presence of anthraquinones. Glycosides, $1.0 \mathrm{~g}$ of extract added to a stopped conical flask in which stripe of sodium picrate paper was suspended then warm gently for about an hour at $37^{\circ} \mathrm{C}$, allow to stand colour change (pink) of picrate paper shows the presence of glycoside.

2.5 Microbial essay: Antibacterial activities of all the extracts of Mangifera indica leaf and Musa paradisiaca root were determined by agar well diffusion method (Okoli et al, 1989) at a concentration of $200 \mathrm{mg} / \mathrm{ml}$ using Mueller Hinton agar (Oxoid, England). Microbial growth was determined by measuring the diameter of the zone inhibition.

2.6 Determination of Minimum Inhibitory Concentration (MIC) and Minimum Bactericidal Concentration (MBC): Using the macro-broth method as described by NCCLS (1998), a two-fold serial dilution of the reconstituted extract was prepared using Mueller Hinton Broth. Each dilution was inoculated with $100 \mathrm{ml}$ of the standardized suspension of the test organism. The cultures were incubated at $37^{\circ} \mathrm{C}$ for $24 \mathrm{~h}$. The MIC was determined as the highest dilution that showed visible growth for MBC, $0.1 \mathrm{ml}$ of all MIC tube 
showing no growth was incubated into sterile Muller Hinton agar plate incubated at $37^{\circ} \mathrm{C}$ for $24 \mathrm{~h}$ and observed for growth. MBC was determined as least concentration showing no growth.

2.7 Statistical analysis: Paired sample T-test was used to analyze the diameter of the zone of inhibition. Values are reported as means of duplicate determination \pm standard deviation.

\section{Results}

The results obtained in Table 1 showed that the ethanolic and hot water extracts of both plants contains alkaloids, flavonoids, Tannins, Saponins, glycosides and anthraquiones as their phytoconstituents. Some of the phytoconsituents present in the ethanolic extracts e.g. tannins were not detected in the hot water extracts of the plants.

Table 2 reveals that the ethanolic extract of $M$. paradisiaca exhibited a high antimicrobial activity against Staphylococcus aureus (10.40+0.04) followed by the ethanolic extract of $M$. indica with inhibition zone diameter of $9.57 \pm 0.06$ against Proteus mirabilis. The hot water extracts of $M$. paradisiaca exhibited a mild antimicrobial activity against Staphylococcus aureus. Both the ethanolic and hot water extracts of both plants had no inhibiting effects on Pseudomonas auruginosa.

Table 3 displays the minimum inhibitory concentrations (MICs) of different crude extracts of M.indica and $M$. paradisiaca. Only the ethanol extract of $M$. paradisiaca and $M$. indica exhibited a bactericidal effect against Staphylococcus aureus and Proteus mirabilis with an index of 1.00 and MBC value of 0.50 respectively.

\section{Discussion}

The medicinal plants Mangifera indica and Musa paradisiaca are being used traditionally for the treatment of dysentery, thostatitis, gonorrheal/syphilis, sore throat and diarrhea of some bacterial activity has been attributed to the presence of some active constituents in the extracts. Studies suggested that the antibacterial activity of $M$. indica and $M$. paradisiacae was probably due to their major component; mangiferin and inulin respective and their properties could be multiple. The plants exhibited variable antibacterial effects against the test isolates. It is natural that there are differences among various antibacterial effects of plant groups. According to the phytochemical properties of plants and to whether the plants are of antimicrobic material or not, there are differences among the species therefore the observed differences in the antibacterial effects of these extracts resulted from this factor.

Extracts from plants are hydrophobic in nature; as a result they distort the cell structure making them to be more permeable. This increase in permeability leads to extensive leakage of critical molecules and ions from the bacterial cells thereby leading to the death of the organism (Rastogi and Methrotra, 2002). This peculiar characteristics of plant extracts bestowed on them the capability of being antimicrobic.

However, in this study, the ethanolic extract of $M$. indica had mild inhibitory effects on Staphylococcus aureus and Escherichia coli while the hot water extract of the same concentration showed no inhibitory effects on these organisms. This may be due to loss of some of the active components in view of their water solubility nature during extraction process of the $M$. indica leaf.

The limited spectrum of activity of the hot water extracts compared with the ethanolic extracts is difficult to explain since all the extracts contained the secondary metabolites, though not in the same proportion. However, the low inhibitory effect could be due to the insolubility of the active compounds in water or the hot water could have caused denaturation of the active compounds.

Muller-Hinton agar (MHA) diffusion method was extensively used to investigate the antibacterial activity of natural antimicrobial substances and plant extracts. However, for solution/extracts with a low antimicrobial activity, one will need a large concentration or volume made possible with holes or cylinders using MHA rather than the disc method with limited application (Bastner et al, 1994). This fact accounts for the low inhibitory effect exhibited by some of the extracts.

The zone of inhibition obtained especially by the ethanol extract of Musa paradisiaca against Staphylococcus aureus $(10.4 \pm 0.04 \mathrm{~mm})$ was found to be higher than that of the primary standard antibiotic used in this study (the antibiotics were effective in milligram amount). This implies a relative effectiveness of the extract over the primary standard antibiotics thus indicating a comparativeness of the activity both in terms of sensitivity and spectrum of activity of the extracts with the standard antibiotics.

As observed in Table 1, Pseudomonas aeruginosa showed resistance to both plant extracts. Pseudomonas aeruginosa is generally known to be resistance to most antibiotics because its genome has unusually large numbers of organic molecules and metabolic regulation, thereby conferring in it the ability to grow in many environments and resist antimicrobial agent (Prescott et al, 2005).

The minimum inhibitory concentration (MIC) of the leaf and root extracts on the test organisms varies as shown in Table 3. This shows that the effect of the leaf and bark extract differs from one organism to the other. 


\section{Conclusion}

The results of this finding thus justified that the traditional therapeutic indication of some extracts from plants were positively correlated with their antimicrobial activities.

\section{References}

[1] Amaechi, I. Natural medicine potentials. Pharmaceutical society of Nigeria (PNS) Conference Proceedings, Abuja (2003)

[2] Nwankwo, I.U. and Amaechi, N. Preliminary phytochemical screening and antibacterial potentials of Anacardium occidentale. Journal of Research in Antimicrobials. 1(2) (2013a) 068-074.

[3] Nwankwo, I.U., Abbey, S.D. and Achi, O.K. Antibacterial activities of some commercially available herbal remedies in Owerri Imo State. Journal of Natural Science Research. 2(10): (2012) 32-36.

[4] Ayodele, Q.S. The effect of herbal remedies. Daily Champion. Thur. Nov. 6 (2003).

[5] Davies, J. Inactivation of antibiotics and the dissemination of resistance genes. Science 264: (1994) 375-382.

[6] Ewujowolo, V. Roos-herbs mystify scientists. Daily summary. Wed. March. 24. (1999).

[7] Isibor, U. and Kingsley, A. The medicinal uses of plants. (Igbala press, Osogbo. (1993) 88-94.

[8] Adodo, A. Nature power: Revised edition. (Don Bosco Training center, Akure 2002)

[9] Grand, A., Wondergen, L.E. and Peter, M. Herbal medicine and health promotion. A comparative studies of herbal drugs in primary health care. Royal Tropical Institute Amsterdan. (1990) 77-85.

[10] Gill, S. Ethnomedical uses of plants in Nigeria. $2^{\text {nd }}$ edition. (Uniben press, Benin City 1992) 414-169.

[11] Bever, B.O. Anti-infectivity activity of higher plants. in: Medicinal plants in tropical West Africa. $1^{\text {st }}$ edition. (Cambridge University press, Great Britain 1986) 123-126.

[12] Adegoke, A.A. and Adebayo, B.C. Antibacterial activity and phytochemical analysis of leaf Extracts of Lasienthera africanum. Afr. Journ. of Biotech. 8(1): (2009a): 077-080.

[13] Adegoke, A.A. and Adebayo, B.C. Phytochemical composition and antimicrobial effects of Corchorus olitorius leaf extracts on four bacterial isolates. J. of Med. Plants Res. 3(3) (2009b); 155-159.

[14] Trease, G.E. and Evans, W.C. Textbook of pharmacology. 12 ${ }^{\text {th }}$ edition (Balliere Tridal and company publisher, London. 1984) 343383.

[15] Okoli, F.C., Opara, A.N. and Metwolly, A.M. Susceptibility testing methods. J. pharm. Med. Sci. 2(4) (1989) 198.

[16] National committee for clinical laboratory standard (NCCLS) Methods for dilution in antimicrobial susceptibility. Test villanova. Ninth information suppl. 25: (1998) 23-29.

[17] Rastogi, R.P. and Methrotra, B.N. Glossary of Indian Medicinal plants (National Institute of Science communication, New Delhi, India 2002).

[18] Bastner, A., Pfeiffer, K.P. and Basner, H. Application of diffusion method required by pharmacopocias for testing antibacterial activity of natural compounds. Pharmazie 49: (1994) 512-516

[19] Prescott, L.M., Harley, J.P. and Kleen, D.A. General Characteristics of antimicrobial drugs. in. Microbiology $6^{\text {th }}$ edition. (McGraw Hill New York, New: 2005) 780-785.

Table 1: Phytochemical screening result

\begin{tabular}{|l|l|l|l|l|l|l|}
\hline Solvent of extract & Plant type & Phyto constituents & Tannins & Saponnins & Glycosides \\
\hline & & Alkaloid & Flavonoid & Anthraquiones & + \\
\hline \multirow{2}{*}{ Ethanol } & Mangifera indica & + & + & + & + & + \\
\cline { 2 - 7 } & Musa paradisiaca & + & + & + & + & + \\
\hline \multirow{2}{*}{ Hot water } & Mangifera indica & - & + & + & + & + \\
\cline { 2 - 7 } & Musa paradisiaca & + & + & - & + & + \\
\hline
\end{tabular}

Key: + = present, - = absence

Table 2: Inhibition zone diameter of the extracts against test isolates

\begin{tabular}{|c|c|c|c|c|c|c|}
\hline \multirow[t]{2}{*}{ Test isolate } & \multicolumn{2}{|c|}{ Ethanol extracts } & \multicolumn{2}{|c|}{ Hot water extract } & \multicolumn{2}{|c|}{ Control antibiotics } \\
\hline & 1 & 2 & 1 & 2 & Genta & Tri \\
\hline Staphylococcus aureus & $2.51 \pm 0.03$ & $10.40 \pm 0.04$ & $0.00 \pm 0.00$ & $6.20 \pm 0.04$ & $26.50 \pm 0.06$ & $7.29 \pm 0.09$ \\
\hline Escherichia coli & $0.83 \pm 0.09$ & $1.50 \pm 0.14$ & $0.00 \pm 0.00$ & $4.97 \pm 0.05$ & $31.35 \pm 0.01$ & $6.79 \pm 0.12$ \\
\hline Proteus mirabilis & $9.52 \pm 0.06$ & $0.00 \pm 0.00$ & $2.58 \pm 0.03$ & $0.00 \pm 0.00$ & $25.85 \pm 0.01$ & $5.07 \pm 0.01$ \\
\hline Pseuomonas aeruginosa & $0.00 \pm 0.00$ & $0.00 \pm 0.00$ & $0.00 \pm 0.00$ & $0.00 \pm 0.00$ & $14.75 \pm 0.21$ & $2.61 \pm 0.06$ \\
\hline
\end{tabular}

Key: 1 = M.indica, 2, Musa paradisiacal, Genta $=$ Gentamycin, Tri $=$ Trimethopria

Table 3: MIC and MBC of the plant extract $(\mathrm{mg} / \mathrm{ml})$

\begin{tabular}{|c|c|c|c|c|c|c|c|}
\hline Plant type & Test organisms & \multicolumn{3}{|c|}{ Extracts } & \multicolumn{3}{|c|}{ Hot water } \\
\hline \multirow{6}{*}{ M. indica } & & $\mathrm{MIC}$ & $\mathrm{MBC}$ & $\mathrm{MIC} / \mathrm{MBC}$ & $\mathrm{MIC}$ & $\mathrm{MBC}$ & $\mathrm{MIC} / \mathrm{MBC}$ \\
\hline & Staphylococcus aureus & 100 & $>200$ & $<0.50$ & $>00$ & $>200$ & $<0.50$ \\
\hline & Escherichia coli & 12.50 & $>200$ & $<0.50$ & $>200$ & $>200$ & $<0.50$ \\
\hline & Streptococcus pneumoniae & 100 & $>200$ & $<0.50$ & 100 & $>200$ & $<0.50$ \\
\hline & Proteus mirabilis & 50 & 100 & 0.50 & 100 & $>200$ & $<0.50$ \\
\hline & Pseuomonas aeruginosa & $>200$ & $>200$ & $<0.50$ & $>200$ & $>200$ & $<0.50$ \\
\hline \multirow{5}{*}{$\begin{array}{l}\text { Musa } \\
\text { paradisiaca }\end{array}$} & Staphylococcus aureus & 100 & 100 & 100 & 50 & $>200$ & $<0.50$ \\
\hline & Escherichia coli & 100 & $>200$ & $<0.50$ & 50 & $>200$ & $<0.50$ \\
\hline & Streptococcus pneumoniae & $>200$ & $>200$ & $<0.50$ & 100 & $>200$ & $<0.50$ \\
\hline & Proteus mirabilis & $>200$ & $>200$ & $<0.50$ & $>200$ & $>200$ & $<0.50$ \\
\hline & Pseuomonas aeruginosa & $>200$ & $>200$ & $<0.50$ & $>200$ & $>200$ & $<0.50$ \\
\hline
\end{tabular}

